\title{
Simplifying Procedures to Increase Competitiveness at In Vitro Propagation of the Olive Cultivar 'Galega Vulgar'
}

\author{
A. Peixe ${ }^{1, \text { a }}$, R. Lourenço ${ }^{1}$, A. Raposo ${ }^{1}$, A.P. Jacob ${ }^{2}$, C. Campos ${ }^{1}$, E. Macedo ${ }^{1}$ and \\ H. Cardoso ${ }^{1}$ \\ ${ }^{1}$ Universidade de Évora, ICAM - Lab. Melhoramento e Biotec. Vegetal, Ap. 94, 7002-554 \\ Évora, Portugal \\ ${ }^{2}$ Inst. Politécnico de Santarém - Escola Superior Agrária, S. Pedro, 2001-904 Santarém, \\ Portugal
}

Keywords: 'Galega Vulgar', in vitro, micropropagation, propagation, olive, Olea

\begin{abstract}
With the aim to reduce fees of a micropropagation protocol for the Portuguese olive cultivar 'Galega Vulgar', expensive Difco Bacto-Agar ${ }^{(3)}$ was replaced by commercial agar-agar, and the analysed data revealed no significant differences between the two agars, for both the explants multiplication rate and the rooting capacity. The replacement of the $O M$ vitamin complex by Tonosol ${ }^{\circledR}$, a commercial vitamin formulation, was also evaluated, and, for the two vitamin sources, both, the multiplication and the rooting capacity of the explants, didn't present significantly different values. Concerning the OM basal media salts, trials were carried-out for its replacement by Substral $^{\circledR}$, a liquid commercial fertilizer. This replacement was unsuccessful, with the cultured explants presenting growth abnormalities and significantly lower multiplication rates. Even with low-cost culture media formulations, the use of semisolid media for micropropagation it is always associated to high labour fees, due to the systematic sub-cultures. To overcome that problem, trials using the RITA ${ }^{\circledR}$ temporary immersion system, were also performed.
\end{abstract}

\section{INTRODUCTION}

The olive cultivar 'Galega Vulgar' stands for almost $70 \%$ of all the Portuguese olive orchards. Traditionally multiplied by hardwood cuttings and by grafting over seedlings, this cultivar revealed to be recalcitrant to the multiplication by semi-hardwood cuttings under mist. Due to its contribution for the typical characteristics of the Portuguese olive oil it seams absolutely necessary to look for alternative multiplication procedures and, in vitro micropropagation, it is one possibility.

The first known reports dealing with in vitro propagation of olive arise from the mid seventy's, with researchers trying to optimize the mineral media formulations for all of the culture stages, in order to establish a micropropagation protocol that would suit all olive cultivars. The OM medium (Rugini, 1984), the MSI, original MS medium (Murashige and Skoog, 1962), modified by Fiorino and Leva (1986) and the MSM, also original MS medium modified by Leva et al. (1992), are considered up-to-now as the most suitable ones for olive micropropagation, but they proved not to be effective for all cultivars (Grigoriadou et al., 2002). We tested all these media formulations with the cultivar 'Galega Vulgar' and considered the OM formulation as the must suitable for all the in vitro culture stages.

Growth regulators belong to the most important components of the in vitro culture media. Since Rugini (1984) zeatin has been widely accepted as the only cytokinin capable of inducing satisfactory growth of olive explants. However, García-Férriz et al. (2002) replaced it by thidiazuron (TDZ) and 6-benzylaminopurine (BAP). Recently, for the cultivar 'Galega Vulgar', zeatin was successfully replaced by coconut water and BAP for both, initiation and multiplication stages of in vitro culture (Peixe et al., 2007).

A significant contribution for in vitro culture of olives was also given by Leva et al. $(1992,1994)$ by replacing sucrose with mannitol. They observed that the increased

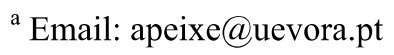

Proc. III ${ }^{\text {rd }}$ IS on Acclim. and Establt. of Micropropagated Plants 